\title{
Gestational diabetes associated with incident diabetes in childhood and youth: a retrospective cohort study
}

\author{
Andrea L. Blotsky MD MSc, Elham Rahme PhD, Mourad Dahhou MSc, Meranda Nakhla MD MSc, \\ Kaberi Dasgupta MD MSc
}

Cite as: CMAJ 2019 April 15;191:E410-7. doi: 10.1503/cmaj.181001

\begin{abstract}
BACKGROUND: Indicators of childhoodand youth-onset diabetes may be useful for early detection of diabetes; there is a known association between composite exposure of parental type 2 diabetes and gestational diabetes mellitus with childhood- and youth-onset diabetes. We examined associations between gestational diabetes mellitus and incidence of childhood- and youth-onset diabetes in offspring.
\end{abstract}

METHODS: Using public health insurance administrative databases from Quebec, Canada, we randomly selected singleton live births with maternal gestational diabetes mellitus (1990-2007) and matched them 1:1 with singleton live births without gestational diabetes mellitus. Follow-up was to Mar. 31, 2012. We examined associations of diabetes in offspring with maternal gestational diabetes mellitus through unadjusted and adjusted Cox proportional hazards models. In secondary analyses, we separately considered age groups ranging from birth to age 12 years, and age 12 to 22 years.

RESULTS: Incidence of pediatric diabetes (per 10000 person-years) was higher in offspring born to mothers with gestational diabetes mellitus $(4.52,95 \%$ confidence interval $[\mathrm{Cl}]$ 4.47-4.57) than in mothers without gestational diabetes mellitus $(2.4,95 \% \mathrm{Cl} 2.37-2.46)$. In an adjusted Cox proportional hazards model, maternal gestational diabetes mellitus was associated with development of pediatric diabetes overall (birth to age 22 yr: hazard ratio [HR] 1.77, 95\% Cl 1.41-2.22), during childhood (birth to age $12 \mathrm{yr}$ : $\mathrm{HR} 1.43,95 \% \mathrm{Cl} 1.09$ 1.89 ), and in youth (age 12 to $22 \mathrm{yr}$ : HR 2.53, 95\% Cl 1.67-3.85).

INTERPRETATION: Gestational diabetes mellitus is associated with incident diabetes in offspring during childhood and adolescence. Future studies are needed to examine longer-term outcomes in patients with pediatric diabetes with a maternal history of gestational diabetes mellitus, to ascertain how they compare with other patients with childhood- or youth-onset diabetes, in terms of disease severity and outcomes.
M ore than $90 \%$ of childhood- and youth-onset diabetes in Canada is type 1 diabetes. ${ }^{1,2}$ The peak prevalence of persistent autoantibodies to islet cell antigens occurs by age 2 years, ${ }^{3}$ with some individuals progressing to type 1 diabetes years later on in life. Indicators of higher likelihood of progression (e.g., recurrent enteroviral infections or absence of rotavirus vaccination, ${ }^{4,5}$ higher maternal or paternal age ${ }^{6}$ ) could potentially facilitate early detection and management. Underscoring the importance of early detection and management, we previously showed that about one-quarter of children and youth with newonset type 1 diabetes present with diabetic ketoacidosis at diagnosis, an avoidable acute complication of type 1 diabetes. ${ }^{7}$

A large retrospective cohort study from Sweden, ${ }^{8}$ where more than $90 \%$ of childhood-and youth-onset diabetes is type 1 diabetes, ${ }^{9}$ showed a 6.2-fold higher incidence rate ratio (IRR) for childhood- and youth-onset diabetes with maternal type 1 diabetes and a 7.6-fold higher IRR with paternal type 1 diabetes. ${ }^{8}$ The IRR was 1.9 times higher for a composite exposure of maternal type 2 diabetes and gestational diabetes mellitus versus neither maternal condition, and 2.5 times as high with versus without paternal diabetes.

In a large retrospective cohort, we previously showed gestational diabetes mellitus and gestational hypertension to be indicators of incident diabetes, hypertension and cardiovascular disease or mortality in mothers, and of incident diabetes in fathers. ${ }^{10,11}$ Using the same cohort, we examined maternal gestational diabetes mellitus as a risk indicator of diabetes in children and youth. 


\section{Methods}

\section{Data sources}

We used provincial health administrative data in the Canadian province of Quebec, merged with information from the birth and death registries. Health administrative databases are maintained by the Régie de l'assurance maladie du Québec (RAMQ) for the public health insurance plan that covers outpatient and in-patient physician services and all costs of acute hospital care for all residents. The health administrative Physician Services Claims and Hospitalization Discharge Diagnoses databases include procedural and diagnostic codes for physician visits (International Classification of Diseases, 9th Revision [ICD-9]) and hospital discharge diagnoses (ICD-9 until April 2006; International Classification of Diseases, 10th Revision [ICD-10] thereafter). Birth and death registries are held at the Institut de la statistique du Québec. The birth registry includes data from the Declaration of Birth that parents are legally required to complete within 30 days of delivery. Questions include maternal level of education, country of birth (mother and father) and first language (mother and father); the sex, gestational age and birth weight of the child are also included.

The RAMQ identified women aged 20-44 years with a singleton live birth between Apr. 1, 1990, and Dec. 31, 2007, with 2 or more outpatient physician billing diagnoses for gestational diabetes mellitus within 6 months of delivery, a diagnosis of gestational diabetes mellitus recorded at hospital discharge, or both. Corresponding fathers and offspring were identified. Motheroffspring-father groupings are hereafter termed "triads." Only complete triads were retained.

For each mother with gestational diabetes mellitus, the RAMQ randomly selected a matched control from among the cohort of mothers with singleton live births between Apr. 1, 1990, and Dec. 31, 2007, who met the following criteria: 1) absence of gestational diabetes mellitus, 2) singleton live birth in the same calendar year, 3) residence in same health administrative territory and 4) same age group (20-24 yr, 25-29 yr, 35-39 yr and 40-44 yr). Corresponding fathers and offspring were identified to form mother-offspring-father triads.

The Institut de la statistique du Québec used a probabilistic matching strategy ${ }^{12}$ to extract additional data on these gestational diabetes mellitus and non-gestational diabetes mellitus triads from the birth registry and, when applicable, the death registry.

Triads were excluded if either parent or corresponding matched parents had cardiovascular disease or heart failure. This was defined as at least 1 hospital admission, discharge date within the 3 years preceding the calendar birth year of their child, with any diagnosis of myocardial infarction or congestive heart failure, or a procedural code for coronary angioplasty or implantation of a cardiac stent. Diabetes is a risk factor for cardiovascular disease; ${ }^{13}$ exclusions related to cardiovascular disease or heart failure were based on the possibility of undiagnosed diabetes in these parents. Although these conditions are uncommon in new parents who are usually young to middle-aged, we made these exclusions because we were asked to limit the data requested as much as possible, for privacy and confidentiality reasons, despite anonymization. We excluded all triads with 1 or more diagnostic codes for diabetes in the father during the 3 years before delivery or in the mother for the same period, but excluding the weeks of pregnancy. When we excluded a triad, we also excluded its matched triad.

To further ensure confidentiality, as required by the Commission d'accès à l'information du Québec, the RAMQ did not provide specific birth dates; instead, it provided the offspring's birth month and year and the age group of mothers and fathers (5-year brackets) at the time of delivery. We defined the 15th day of the birth month as the delivery date. We had accurate information on gestational age as this was directly available from the birth registry, reported in weeks. We considered the pregnancy period to comprise the estimated delivery date and the weeks before this estimated date corresponding to the reported gestational age, plus 2 additional weeks prior.

\section{Exposure and outcomes}

The primary exposure was maternal gestational diabetes mellitus as described above, through a validated definition. ${ }^{14,15}$ Bowker and colleagues validated ICD-10 codes specific to gestational diabetes mellitus, in any diagnosis field of any outpatient clinic visit during 270 days or less before hospital admission related to delivery, against laboratory-diagnosed gestational diabetes mellitus. ${ }^{14}$ The sensitivity and specificity were $92 \%$ and $97 \%$, respectively. In another study, ICD-9 or ICD-10 codes specific to gestational diabetes mellitus in any diagnosis field of the hospital admission related to the delivery were validated against the Alberta Perinatal Health Program database. ${ }^{15}$ The sensitivity and specificity were $86 \%$ and $99 \%$, respectively. We applied a definition of any ICD code specific to gestational diabetes mellitus in the hospital admission related to delivery or 2 or more outpatient clinic visits with codes specific to gestational diabetes mellitus.

The primary outcome was incident diabetes in offspring. The follow-up was to the end of the period of observation (Mar. 31, 2012), departure from the province or death. Diabetes was defined as 1 hospital discharge diagnosis or 2 outpatient visit diagnoses for diabetes within a 2-year time period, a definition validated in children, youth and adults in Canada. ${ }^{16-19}$ Specifically in children and youth, this definition showed a sensitivity of $100 \%$ and specificity of $93 \%$ in a validation study from Ontario ${ }^{16}$ and a sensitivity of $94.2 \%$ and specificity of $99.9 \%$ in a validation study from Manitoba. ${ }^{19}$ In health administrative data, type 1 diabetes and type 2 diabetes have historically not been distinguished, but most children and youth with diabetes in Canada (>90\%) have type 1 diabetes, as shown in previous Canadian studies. ${ }^{1,2}$ Further, through a chart review in our Quebec population of children and youth with diabetes, we have found that $95 \%$ of those with diabetes have type 1 diabetes (McGill University Health Centre [Montreal Children's Hospital], Hôpital Maisonneuve-Rosemont and Centre hospitalier universitaire SainteJustine, unpublished data, Apr. 1, 2002, to Mar. 31, 2011).

\section{Covariates}

Covariates and potential confounding variables included gestational age, macrosomia (i.e., birth weight over $4000 \mathrm{~g}$ ), sex of offspring, maternal demographic factors (mother's years of education, country of birth, first language, age group, material deprivation level), history of prior pregnancy in the mother (previous pregnancy, prior viable pregnancy and prior stillbirth) and autoimmune disease in the mother. 
Offspring considered "European" were those whose mothers were born in North America, Europe or Australia and whose mother's first language was of European origin. We used maternal country of birth and first language to also classify offspring as Indigenous, AfroCaribbean, Asian, Central/South American, West Asian and "other."

Level of material deprivation was captured through the Institut national de santé publique du Québec index, ${ }^{20}$ derived from a ranking of census dissemination area-level scores based on proportion without high school diploma, employment:population ratio, and average income (census data). Dissemination areas are divided into quintiles (least to most deprived); the RAMQ generates the index through a program that links 6-digit postal code information to an algorithm.

Maternal autoimmune disease was defined as the presence of at least 1 ICD-9 or ICD-10 diagnostic code for autoimmune conditions, including multiple sclerosis, celiac disease, sarcoidosis, Behçet syndrome, thyroid conditions, Cushing syndrome, hyperaldosteronism, primary thrombocytopenia, various types of allergic alveolitis, eosinophilic pneumonitis, psoriasis, urticaria, bullous pemphigoid, lupus, scleroderma, dermatomyositis, polymyositis, rheumatoid arthritis, sacroiliitis, ankylosing spondylitis, inflammatory bowel disease and myasthenia gravis.

\section{Statistical analysis}

We performed the analyses using SAS (version 9.3). We examined baseline characteristics (means and standard deviations, numbers and proportions), plotted Kaplan-Meier curves, and computed incidence rates of diabetes (number/10 000 personyears) by status of maternal gestational diabetes mellitus. We examined associations of diabetes in offspring with maternal gestational diabetes mellitus through unadjusted and adjusted Cox proportional hazards models. Follow-up was from birth to up to 22 years.

In secondary analyses, we separately considered age groups of birth to age 12 years and age 12 to 22 years. Insulin resistance rises during puberty which, coupled with an increase in weight or low activity levels, could render adolescents particularly vulnerable; ${ }^{21}$ hence our interest in examining childhood and adolescence separately in secondary analyses. We adjusted multivariate models for sex, gestational age ( $<32 \mathrm{wk}, 32$ to $37 \mathrm{wk}$ compared with $>37 \mathrm{wk}$ reference group), birth weight (<3000 g, > 4000 g compared with $3000 \mathrm{~g}$ to $4000 \mathrm{~g}$ reference), ethnocultural background (European or non-European), material deprivation (4 least deprived quintiles or most deprived quintile), previous pregnancy (yes or no) and maternal autoimmune disease (yes or no).

\section{Ethical approval}

This study was approved by the Commission d'accès à l'information du Québec and the Institutional Review Board of the McGill University Health Centre. All data received by the research team were anonymized.

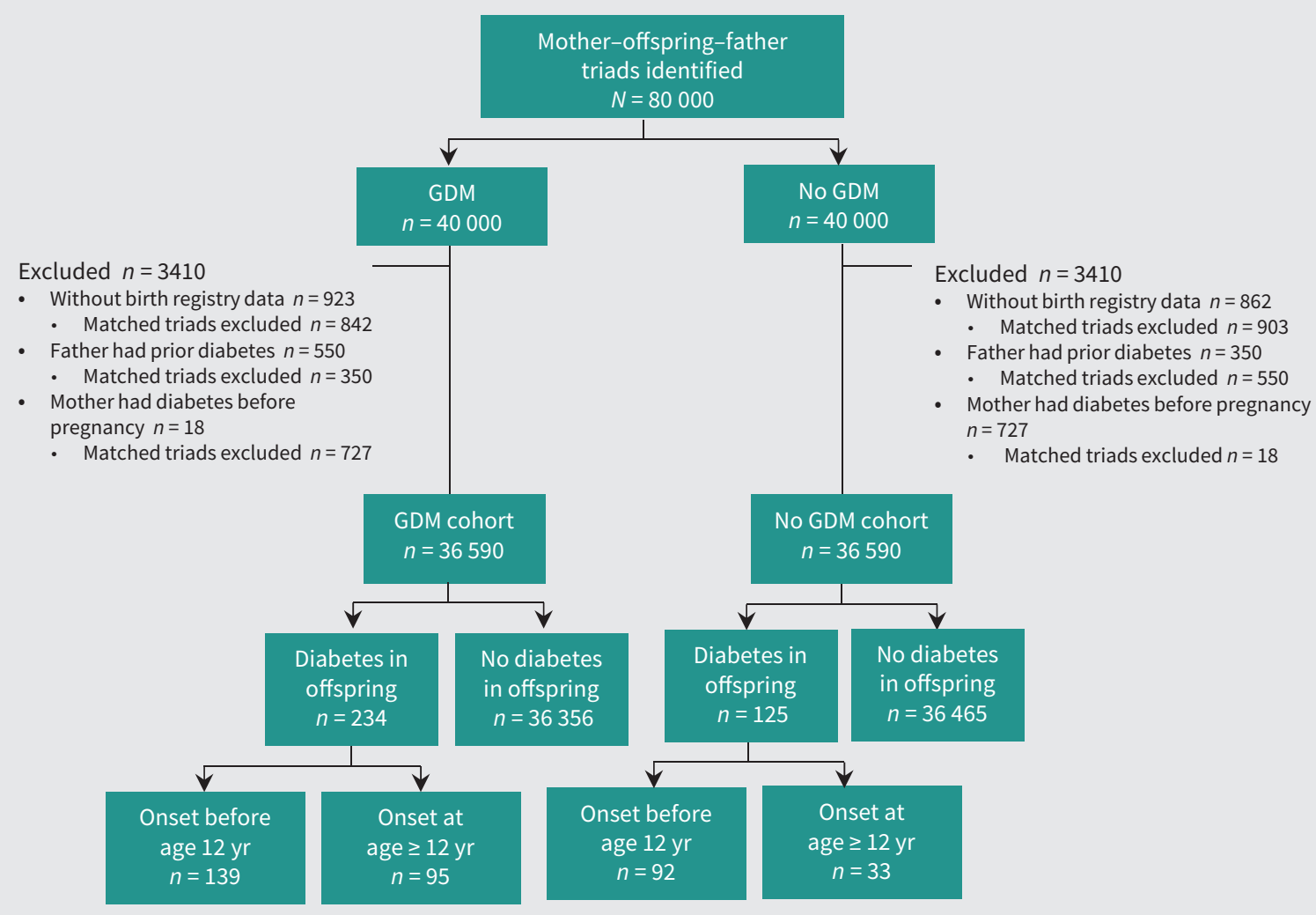

Figure 1: Flowchart showing selection of gestational diabetes mellitus (GDM) and non-GDM cohorts. Triads and matched triads were excluded if the father had at least 1 diabetes code during 3 years before delivery, or if the mother had at least 1 diabetes code during 3 years before delivery but not including pregnancy period (estimated by gestational age). 


\section{Results}

Among the 80000 triads initially delineated at the RAMQ, we included 73180 (91.5\%) in our analyses (Figure 1). Slightly less than half the offspring were girls (47.8\% offspring of mothers with and $48.4 \%$ offspring of mothers without gestational diabetes mellitus; Table 1). A higher proportion of mothers with gestational diabetes mellitus compared with mothers without were non-European ( $23.4 \%$ v. $18.3 \%$ ), did not graduate from high school ( $25.7 \%$ v. $19.1 \%)$, or were from the most materially deprived quintile (23.7\% v. $19.4 \%$ ); a higher proportion also had a delivery before 37 weeks (10.2\% v. 6.7\%), had a previous live birth (50\% v. $27.6 \%$ ), or had a prior stillbirth (3.8\% v. $2.6 \%)$. A higher proportion of offspring with maternal gestational diabetes mellitus compared with mothers without had macrosomia ( $11.7 \%$ v. $9.5 \%)$. A higher proportion of mothers with gestational diabetes mellitus compared with mothers without had autoimmune disease (29.9\% v. $26.8 \%$ ).

\section{Association of diabetes with gestational diabetes mellitus}

Three hundred and fifty-nine $(0.49 \%)$ offspring developed diabetes (234 [0.32\%] from birth to age $12 \mathrm{yr}$ and 125 [0.27\%] from age 12 to $22 \mathrm{yr}$ ). The Kaplan-Meier curves illustrate that a higher proportion of offspring whose mothers had gestational diabetes mellitus developed diabetes themselves over time compared with offspring whose mothers did not have gestational diabetes (Figure 2). The incidence of diabetes per 10000 person-years in offspring born to mothers with gestational diabetes mellitus was 4.52 (95\% confidence interval $[\mathrm{Cl}]$ 4.47-4.57) compared with 2.41 (95\% Cl 2.37-2.46) in mothers without gestational diabetes mellitus. After we adjusted for sex, gestational age group, birth weight group, ethnicity, material deprivation, previous pregnancy and maternal autoimmune disease, gestational diabetes mellitus was associated with diabetes in offspring from birth to age 22 years (adjusted hazard ratio [HR] 1.77, 95\% Cl 1.41-2.22 [Table 2]). This association was also found between birth and age 12 years (adjusted HR 1.43, 95\% Cl 1.091.89) and between age 12 and 22 years (adjusted HR 2.53, 95\% Cl 1.67-3.85).

There were signals of potential associations with diabetes in offspring for female sex (adjusted HR 1.23, 95\% Cl 0.99-1.52), birth weight less than $3000 \mathrm{~g}$ (adjusted HR 1.24, $95 \% \mathrm{Cl} 0.95-1.63)$, and birth weight $4000 \mathrm{~g}$ or more (adjusted HR 1.35, 95\% Cl 0.98-1.85).
Table 1 (part 1 of 2): Characteristics by status of gestational diabetes mellitus in mother

\section{mellitus in mother}

\section{Characteristic}

Female sex

\section{Gestational age, wk}

Mean gestational age at birth \pm SD

Gestational age category

$<32$
$32-37$
$>37$

\section{Weight status at birth, $g$}

Mean birth weight \pm SD

Overall
Girls
Boys
Birth weight category $\dagger$

Low birth weight, $<2500$

$<2500$ to $<2999$

Normal birth weight, 3000

to 3999

Macrosomia, $\geq 4000$

Ethnocultural background $\ddagger$

European§
Indigenous
Afro-Caribbean
Asian 9
Central/South American
West Asian
Other
Maternal age categories, yr
$<30$
$30-40$
$>40$

Maternal education, $\mathrm{yr}^{\star \star}$

$\begin{array}{lc}<12 & 8861(25.7) \\ 12-14 & 8326(24.1) \\ 14-18 & 13907(40.3) \\ >18 & 3454(10)\end{array}$

16374 (44.8)

18924 (51.7)

$1292(3.5)$

28035 (76.6)

$303(0.83)$

$1343(3.7)$

$2809(7.7)$

542 (1.5)

$2249(6.2)$

$1094(3.0)$

\section{No. without gestational diabetes $(\%)^{\star}$ $n=36590$}

17694 (48.4)

$39.1 \pm 1.83$

$-0.285$

Standardized difference

$-0.011$

$-0.009$

0.107

$-0.094$
Maternal deprivation level, quintiles $\dagger$

\begin{tabular}{|c|c|c|c|}
\hline 2 least deprived quintiles & $12751(35.8)$ & $14648(41.2)$ & -0.111 \\
\hline $\begin{array}{l}2 \text { quintiles at intermediate } \\
\text { level }\end{array}$ & $14431(40.5)$ & $14011(39.4)$ & 0.0224 \\
\hline Most deprived quintile & $8461(23.7)$ & $6911(19.4)$ & 0.105 \\
\hline
\end{tabular}

$3351 \pm 0.532$
$3289 \pm 0.511$

$3410 \pm 0.545$

0.039

0.0523

0.0252

0.030

$-0.015$

$-0.049$

0.070

$-0.125$

0.0575

0.0354

0.135

$-0.0121$

0.0478

$-0.0049$

$16374(44.8) \quad 0$

$18924(51.7) \quad 0$

$1292(3.5) \quad 0$

$6593(19.1) \quad 0.158$

$7537(21.8) \quad 0.054$

$15780(45.7) \quad-0.110$

$4620(13.3) \quad-0.105$

0.111

0.105 
Table 1 (part 2 of 2): Characteristics by status of gestational diabetes mellitus in mother

\begin{tabular}{|c|c|c|c|}
\hline Characteristic & $\begin{array}{c}\text { No. with } \\
\text { gestational } \\
\text { diabetes }(\%)^{\star} \\
n=36590\end{array}$ & $\begin{array}{c}\text { No. without } \\
\text { gestational } \\
\text { diabetes }(\%)^{\star} \\
n=36590\end{array}$ & $\begin{array}{l}\text { Standardized } \\
\text { difference }\end{array}$ \\
\hline \multicolumn{4}{|c|}{ Maternal pregnancy history } \\
\hline Prior pregnancy & $18777(51.3)$ & $10521(28.8)$ & 0.473 \\
\hline Prior stillbirth & $1379(3.8)$ & $932(2.6)$ & 0.07 \\
\hline \multicolumn{4}{|l|}{ Prior viable pregnancies } \\
\hline 0 & $18293(50)$ & $26474(72.4)$ & -0.471 \\
\hline 1 & $11590(31.7)$ & $6441(17.6)$ & 0.331 \\
\hline$\geq 2$ & $6707(18.3)$ & $3675(10.0)$ & 0.239 \\
\hline $\begin{array}{l}\text { Maternal autoimmune } \\
\text { disease } \ddagger \ddagger\end{array}$ & 10955 (29.9) & $9812(26.8)$ & 0.0693 \\
\hline \multicolumn{4}{|c|}{ 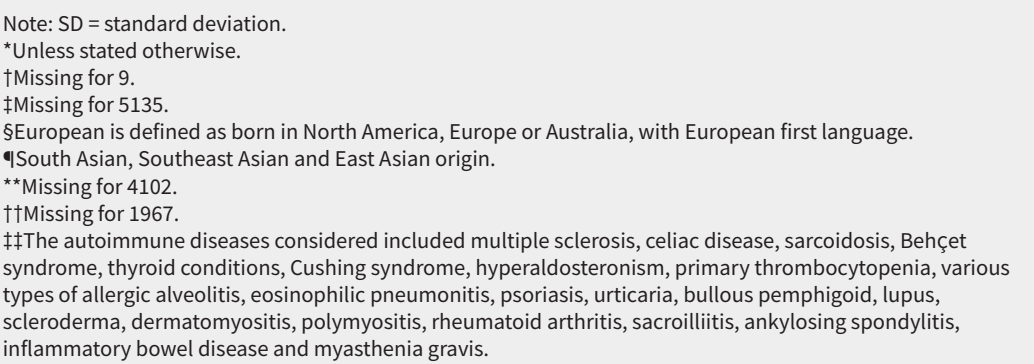 } \\
\hline
\end{tabular}

In the main analyses, we opted to collapse categories regarding origin other than European because of small numbers of individuals who developed diabetes within each group. Origin other than European was not associated with increased risk of diabetes in offspring overall. In univariate models and an exploratory multivariate model that distinguished Indigenous and West Asian categories from other non-European ethnocultural groups, being of Indigenous (birth to age $22 \mathrm{yr}$ : unadjusted HR 3.42, 95\% Cl 1.70-6.90; adjusted HR $3.49,95 \% \mathrm{Cl} 1.67-7.27)$ versus European and being of West Asian origin versus European (birth to age $22 \mathrm{yr}$ : unadjusted HR $1.63,95 \% \mathrm{Cl}$ 1.08-2.44; 1.68 adjusted HR 95\% Cl 1.11-2.53) were associated with diabetes in offspring. However, given small numbers of incident diabetes cases within each non-European ethnocultural group, caution should be exercised in interpreting these findings.

Female sex was associated with incident diabetes between age 12 and 22 years (adjusted HR 1.86, 95\% Cl 1.28-2.70). Gestational age less than 32 weeks (adjusted HR 2.97, 95\% Cl 1.19-7.42) and previous pregnancy in the mother (adjusted HR $1.70,95 \% \mathrm{Cl}$ 1.20-2.54) were also associated with diabetes in offspring between age 12 and 22 years.
A

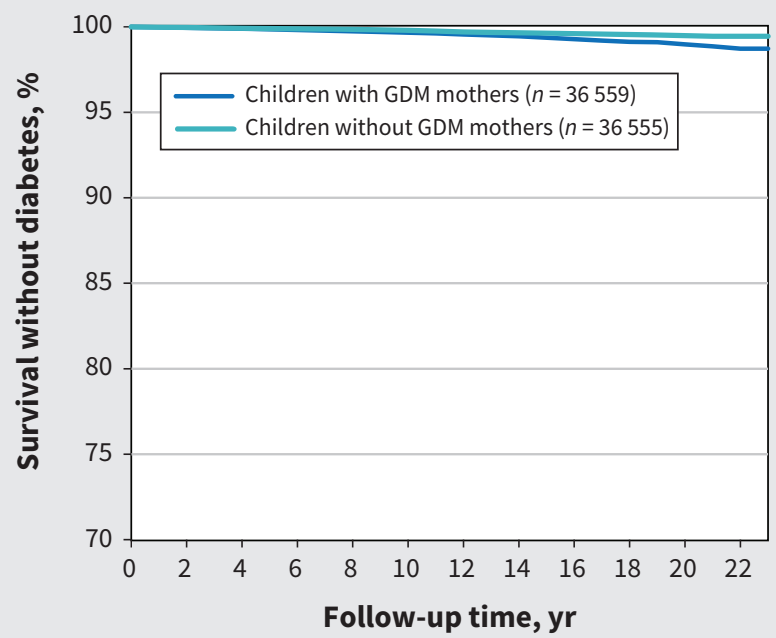

B

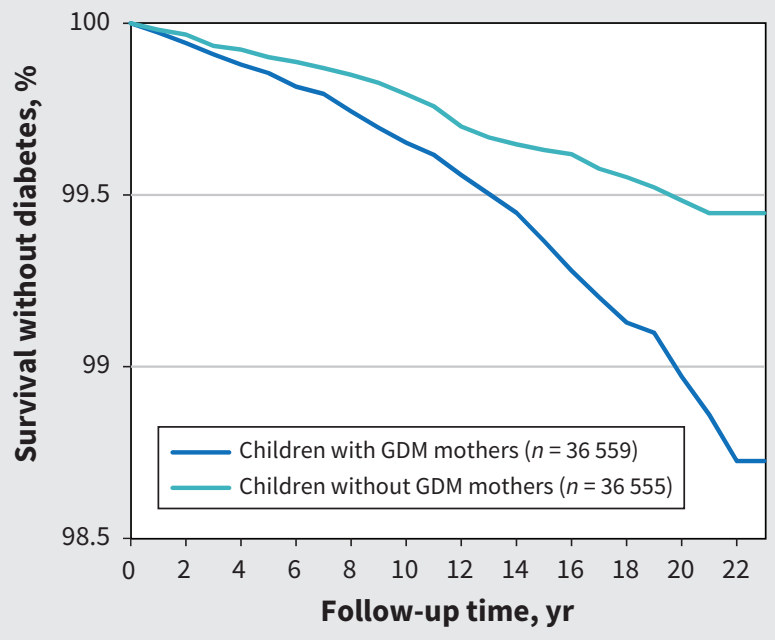

Figure 2: Kaplan-Meier curve for diabetes-free survival in offspring. (A) Y-axis from $0 \%$ to $100 \%$; (B) y-axis from $98.5 \%$ to $100 \%$ to illustrate the differences between groups. Note: GDM = gestational diabetes mellitus. 
Table 2: Hazard ratios for diabetes in children and youth

\begin{tabular}{|c|c|c|c|c|c|c|}
\hline \multirow[b]{2}{*}{ Characteristic } & \multicolumn{2}{|c|}{ Birth to age $22 \mathrm{yr}$} & \multicolumn{2}{|c|}{ Birth to age $12 \mathrm{yr}$} & \multicolumn{2}{|c|}{ Age 12 to $22 \mathrm{yr}$} \\
\hline & $\begin{array}{l}\text { Unadjusted HR } \\
(95 \% \mathrm{Cl})\end{array}$ & $\begin{array}{c}\text { Adjusted HR } \\
(95 \% \mathrm{Cl})\end{array}$ & $\begin{array}{c}\text { Unadjusted HR } \\
(95 \% \mathrm{CI})\end{array}$ & $\begin{array}{c}\text { Adjusted HR } \\
(95 \% \mathrm{CI})\end{array}$ & $\begin{array}{c}\text { Unadjusted HR } \\
(95 \% \mathrm{CI})\end{array}$ & $\begin{array}{c}\text { Adjusted HR } \\
(95 \% \mathrm{CI})\end{array}$ \\
\hline Maternal gestational diabetes & $\begin{array}{c}1.88 \\
(1.51-2.33)\end{array}$ & $\begin{array}{c}1.77 \\
(1.41-2.22)\end{array}$ & $\begin{array}{c}1.52 \\
(1.16-1.97)\end{array}$ & $\begin{array}{c}1.43 \\
(1.09-1.89)\end{array}$ & $\begin{array}{c}2.89 \\
(1.94-4.29)\end{array}$ & $\begin{array}{c}2.53 \\
(1.67-3.85)\end{array}$ \\
\hline Female sex ${ }^{*}$ & $\begin{array}{c}1.18 \\
(0.96-1.45)\end{array}$ & $\begin{array}{c}1.23 \\
(0.99-1.52)\end{array}$ & $\begin{array}{c}0.95 \\
(0.74-1.23)\end{array}$ & $\begin{array}{c}0.99 \\
(0.76-1.29)\end{array}$ & $\begin{array}{c}1.74 \\
(1.22-2.49)\end{array}$ & $\begin{array}{c}1.86 \\
(1.28-2.70)\end{array}$ \\
\hline \multicolumn{7}{|l|}{ Gestational age, wk $\dagger$} \\
\hline$<32$ & $\begin{array}{c}1.66 \\
(0.89-3.13)\end{array}$ & $\begin{array}{c}1.53 \\
(0.78-3.0)\end{array}$ & $\begin{array}{c}1.70 \\
(1.15-2.64)\end{array}$ & $\begin{array}{c}1.29 \\
(0.47-3.50)\end{array}$ & $\begin{array}{c}3.54 \\
(1.56-8.05)\end{array}$ & $\begin{array}{c}2.97 \\
(1.19-7.42)\end{array}$ \\
\hline 32 to 37 & $\begin{array}{c}1.39 \\
(0.96-2.0)\end{array}$ & $\begin{array}{c}1.13 \\
(0.74-1.72)\end{array}$ & $\begin{array}{c}1.29 \\
(0.48-3.46)\end{array}$ & $\begin{array}{c}1.56 \\
(0.97-2.50)\end{array}$ & $\begin{array}{c}0.73 \\
(0.32-1.65)\end{array}$ & $\begin{array}{c}0.42 \\
(0.15-1.18)\end{array}$ \\
\hline \multicolumn{7}{|l|}{ Birth weight category, gł } \\
\hline$<3000$ & $\begin{array}{c}1.31 \\
(1.02-1.67)\end{array}$ & $\begin{array}{c}1.24 \\
(0.95-1.63)\end{array}$ & $\begin{array}{c}1.30 \\
(0.95-1.76)\end{array}$ & $\begin{array}{c}1.17 \\
(0.83-1.65)\end{array}$ & $\begin{array}{c}1.30 \\
(0.86-1.98)\end{array}$ & $\begin{array}{c}1.34 \\
(0.85-2.11)\end{array}$ \\
\hline$>4000$ & $\begin{array}{c}1.38 \\
(1.01-1.88)\end{array}$ & $\begin{array}{c}1.35 \\
(0.98-1.85)\end{array}$ & $\begin{array}{c}1.33 \\
(0.90-1.97)\end{array}$ & $\begin{array}{c}1.33 \\
(0.87-1.98)\end{array}$ & $\begin{array}{c}1.51 \\
(0.91-2.53)\end{array}$ & $\begin{array}{c}1.42 \\
(0.84-2.41)\end{array}$ \\
\hline \multicolumn{7}{|l|}{ Ethnocultural background } \\
\hline Non-European§ & $\begin{array}{c}1.049 \\
(0.79-1.35)\end{array}$ & $\begin{array}{c}1.08^{\star \star} \\
(0.82-1.41)\end{array}$ & $\begin{array}{c}0.98 \\
(0.71-1.37)\end{array}$ & $\begin{array}{c}1.05 \\
(0.76-1.47)\end{array}$ & $\begin{array}{c}0.85 \\
(0.54-1.33)\end{array}$ & $\begin{array}{c}0.80 \\
(0.51-1.27)\end{array}$ \\
\hline \multicolumn{7}{|l|}{ Deprivation level } \\
\hline 4 least deprived quintiles $† \dagger$ & $\begin{array}{c}1.08 \\
(0.83-1.4)\end{array}$ & $\begin{array}{c}1.13 \\
(0.86-1.47)\end{array}$ & $\begin{array}{c}1.23 \\
(0.88-1.72)\end{array}$ & $\begin{array}{c}1.27 \\
(0.90-1.79)\end{array}$ & $\begin{array}{c}0.87 \\
(0.57-1.31)\end{array}$ & $\begin{array}{c}0.91 \\
(0.59-1.34)\end{array}$ \\
\hline Previous pregnancy & $\begin{array}{c}1.12 \\
(0.91-1.38)\end{array}$ & $\begin{array}{c}1.04 \\
(0.84-1.30)\end{array}$ & $\begin{array}{c}1.0 \\
(0.77-1.31)\end{array}$ & $\begin{array}{c}0.96 \\
(0.73-1.26)\end{array}$ & $\begin{array}{c}2.02 \\
(1.42-2.87)\end{array}$ & $\begin{array}{c}1.74 \\
(1.20-2.54)\end{array}$ \\
\hline Maternal autoimmune disease & $\begin{array}{c}1.22 \\
(0.98-1.51)\end{array}$ & $\begin{array}{c}1.14 \\
(0.91-1.42)\end{array}$ & $\begin{array}{c}1.27 \\
(0.97-1.67)\end{array}$ & $\begin{array}{c}1.21 \\
(0.92-1.60)\end{array}$ & $\begin{array}{c}1.34 \\
(0.94-1.93)\end{array}$ & $\begin{array}{c}1.20 \\
(0.82-1.75)\end{array}$ \\
\hline \multicolumn{7}{|c|}{ 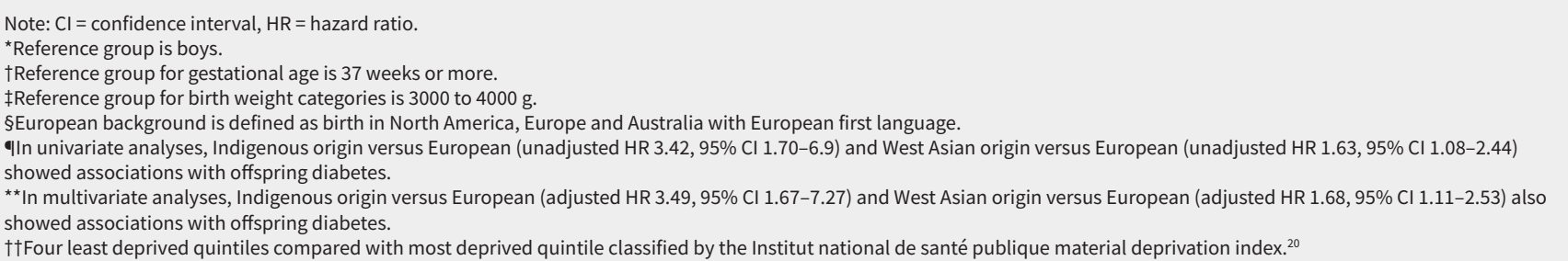 } \\
\hline
\end{tabular}

\section{Interpretation}

Our analyses show that gestational diabetes mellitus is associated with incident diabetes in offspring from birth to age 22 years, both overall and when stratified into childhood (birth to age $12 \mathrm{yr}$ ) and youth (age 12 to $22 \mathrm{yr}$ ) age groups. Although type 1 diabetes and type 2 diabetes in parents are wellestablished risk factors for diabetes, we show that gestational diabetes mellitus may be a risk indicator for diabetes in offspring before age 22 years.

One previous health administrative database study, conducted in Sweden, reported similar findings, observing a combined exposure of maternal gestational diabetes mellitus and type 2 diabetes to be associated with pediatric diabetes (IRR 1.85, 95\% Cl 1.53-2.23). ${ }^{8}$ Our findings show a specific association between maternal gestational diabetes mellitus alone and diabetes in offspring between birth and age 22 years. The Swedish study accounted for both maternal first trimester body mass index (BMI) and large-for-gestational-age birth weight; we accounted for macrosomia.

Although we did not have access to maternal BMI data, either large-for-gestational-age status or macrosomia may be considered a proxy. Status of maternal prepregnancy weight is conclusively associated with macrosomia in offspring. In a 2016 metaanalysis of 60 studies, ${ }^{22}$ mothers with prepregnancy overweight or obesity showed higher risks for macrosomia (odds ratio [OR] $1.70,95 \% \mathrm{Cl} 1.55-1.87$ and OR 2.92, 95\% Cl 2.67-3.20, respectively). Recommendations regarding gestational weight gain are based on maternal prepregnancy BMI. In a 2018 meta-analysis, gestational weight gain higher than the Institute of Medicine guideline was associated with a 1.87 -fold $(95 \% \mathrm{Cl} 1.70-2.06)$ risk increase of macrosomia. ${ }^{23}$ In a 2017 meta-analysis, gestational 
weight gain higher than guideline thresholds was associated with a 1.95 -fold risk increase $(95 \% \mathrm{Cl} 1.79-2.11)$ for macrosomia. ${ }^{24}$ The risk increases for macrosomia paralleled those for large-for-gestational-weight status (large-for-gestational age).

Macrosomia is not only closely related to maternal BMI, but is also, arguably, the more salient variable in an examination of diabetes outcomes in childhood and youth. Adjusting for both macrosomia and maternal prepregnancy BMI or for both largefor-gestational age and maternal prepregnancy BMI may be considered overadjustment.

We observed an association of diabetes in offspring with female sex in adolescence, an association that has previously been described for type 2 diabetes and attributed to heightened insulin resistance during this developmental period. ${ }^{24}$ Although insulin resistance plays an important role in development of type 2 diabetes, the accelerator and overload hypotheses propose that insulin resistance increases destruction (apoptosis) of the insulin-producing $\beta$ cells in the pancreas, heightening the autoimmune reaction to $\beta$ cells in immunologically at-risk individuals and resulting in progression to type 1 diabetes..$^{25}$

Strengths of our study were the use of diagnostic codes related to gestational diabetes mellitus validated in Canada, a large sample size and long duration of follow-up, and a combination of health administrative data with birth registry information, allowing us to account for factors not usually recorded in health administrative data alone, including gestational age, birth weight, sex and ethnocultural background.

\section{Limitations}

One limitation of our study was our inability to distinguish between type 1 and type 2 diabetes in offspring, but the known distribution of type 1 and type 2 in pediatric diabetes allows us to infer that diabetes in offspring was largely type 1 . The cohort included offspring of mothers with gestational diabetes mellitus and of mothers without gestational diabetes mellitus; the mothers were matched on age group but not on absolute age, another potential limitation, given the possibility of some residual maternal age-related confounding.

We did not have information on maternal BMI or weight gain during pregnancy. However, we did have data on offspring macrosomia, a variable that correlates with both, and is included in our analyses. Detailed information on islet cell antibodies and immunologic profiles would have been of interest, but such data are not routinely collected in health administrative data. We did test for an association between maternal autoimmune disease and diabetes in offspring but did not observe a conclusive association.

We used health administrative and birth registry databases for this study. Although these data sets provide large numbers and long duration of follow-up, they are limited by the type of data collected. For example, there is no information collected and recorded on health behaviours such as smoking, physical activity or food intake. There is no specific information gathered on ethnocultural background. In our analyses, we used birth registry information on maternal country of birth and language spoken to classify as "European" or "non-European" in background. We acknowledge that there is definite potential for misclassification.
For example, a person of Indigenous origin born in Canada who does not speak an Indigenous language would be classified as European in origin. Similarly, a person of South Asian origin born in Canada who speaks English as a first language would also be classified as European. Nonetheless, many would be accurately classified and therefore we retained our method of ethnocultural classification. We acknowledge that the method we used to classify by ethnocultural background has not been validated.

\section{Conclusion}

Gestational diabetes mellitus is associated with incident diabetes in offspring during childhood and adolescence. This indicator, like others, has the potential to stimulate clinicians, parents and even children and youth to consider the possibility of diabetes if offspring of a mother with gestational diabetes mellitus develop signs and symptoms such as polyuria, polydipsia, weight loss or fatigue. Future studies are needed to examine longerterm outcomes in patients with pediatric diabetes with a history of maternal gestational diabetes mellitus, to ascertain how they compare with other patients with childhood- or youth-onset diabetes, in terms of disease severity and outcomes.

\section{References}

1. Amed S, Nuernberger K, McCrea P, et al. Status report on the British Columbia Paediatric Diabetes Program. Vancouver: Provincial Health Services Authority; 2010.

2. Shulman R, Miller FA, Stukel TA, et al. Resources and population served: a description of the Ontario Paediatric Diabetes Network. CMAJ Open 2016;4:E141-6.

3. Rewers M, Ludvigsson J. Environmental risk factors for type 1 diabetes. Lancet 2016;387:2340-8.

4. Stene LC, Oikarinen S, Hyöty $\mathrm{H}$, et al. Enterovirus infection and progression from islet autoimmunity to type 1 diabetes: the Diabetes and Autoimmunity Study in the Young (DAISY). Diabetes 2010;59:3174-80.

5. Perrett KP, Jachno K, Nolan TM, et al. Association of rotavirus vaccination with the incidence of type 1 diabetes in children. JAMA Pediatr 2019;173:280-2.

6. Cardwell CR, Carson DJ, Patterson CC. Parental age at delivery, birth order, birth weight and gestational age are associated with the risk of childhood Type 1 diabetes: a UK regional retrospective cohort study. Diabet Med 2005;22:200-6.

7. Nakhla M, Rahme E, Simard M, et al. Risk of ketoacidosis in children at the time of diabetes mellitus diagnosis by primary caregiver status: a population-based retrospective cohort study. CMAJ 2018;190:E416-21.

8. Hussen HI, Persson M, Moradi T. Maternal overweight and obesity are associated with increased risk of type 1 diabetes in offspring of parents without diabetes regardless of ethnicity. Diabetologia 2015;58:1464-73.

9. Rawshani A, Landin-Olsson M, Svensson AM, et al. The incidence of diabetes among 0-34 year olds in Sweden: new data and better methods. Diabetologia 2014;57:1375-81.

10. Pace R, Brazeau AS, Meltzer S, et al. Conjoint associations of gestational diabetes and hypertension with diabetes, hypertension, and cardiovascular disease in parents: a retrospective cohort study. Am J Epidemiol 2017;186:1115-24.

11. Dasgupta K, Ross N, Meltzer S, et al. Gestational diabetes mellitus in mothers as a diabetes predictor in fathers: a retrospective cohort analysis. Diabetes Care 2015;38:e130-1.

12. Fellegi IP, Sunter AB. A theory for record linkage. J Am Stat Assoc 1969;64:1183210. doi:10.1080/01621459.1969.10501049.

13. Diabetes mellitus: a major risk factor for cardiovascular disease. A joint editorial statement by the American Diabetes Association; The National Heart, Lung, and Blood Institute; The Juvenile Diabetes Foundation International; The National Institute of Diabetes and Digestive and Kidney Diseases; and The American Heart Association. Circulation 1999;100:1132-3.

14. Bowker SL, Savu A, Donovan LE, et al. Validation of administrative and clinical case definitions for gestational diabetes mellitus against laboratory results. Diabet Med 2017;34:781-5. 
15. Bowker SL, Savu A, Lam NK, et al. Validation of administrative data case definitions for gestational diabetes mellitus. Diabet Med 2017;34:51-5.

16. Guttmann A, Nakhla M, Henderson M, et al. Validation of a health administrative data algorithm for assessing the epidemiology of diabetes in Canadian children. Pediatr Diabetes 2010;11:122-8.

17. Leong A, Dasgupta K, Bernatsky S, et al. Systematic review and meta-analysis of validation studies on a diabetes case definition from health administrative records. PLoS One 2013;8:e75256.

18. Leong A, Dasgupta K, Chiasson JL, et al. Estimating the population prevalence of diagnosed and undiagnosed diabetes. Diabetes Care 2013;36:3002-8.

19. Dart AB, Martens PJ, Sellers EA, et al. Validation of a pediatric diabetes case definition using administrative health data in Manitoba, Canada. Diabetes Care 2011;34:898-903.

20. Pampalon R, Hamel D, Gamache P, et al. A deprivation index for health planning in Canada. Chronic Dis Can 2009;29:178-91.
21. Bloch CA, Clemons P, Sperling MA. Puberty decreases insulin sensitivity. J Pediatr 1987;110:481-7.

22. Liu P, Xu L, Wang Y, et al. Association between perinatal outcomes and maternal pre-pregnancy body mass index. Obes Rev 2016;17:1091-102.

23. Goldstein RF, Abell SK, Ranasinha S, et al. Gestational weight gain across continents and ethnicity: systematic review and meta-analysis of maternal and infant outcomes in more than one million women. BMC Med 2018;16:153.

24. Goldstein RF, Abell SK, Ranasinha S, et al. Association of gestational weight gain with maternal and infant outcomes: a systematic review and meta-analysis. JAMA 2017;317:2207-25.

25. Rosenbloom AL, Joe JR, Young RS, et al. Emerging epidemic of type 2 diabetes in youth. Diabetes Care 1999;22:345-54.

26. Polsky S, Ellis SL. Obesity, insulin resistance, and type 1 diabetes mellitus. Curr Opin Endocrinol Diabetes Obes 2015;22:277-82.

\section{Competing interests: None declared.}

This article has been peer reviewed.

Affiliations: Department of Medicine (Blotsky, Rahme, Dasgupta), McGill University; Centre for Outcomes Research and Evaluation (Blotsky, Rahme, Dahhou, Nakhla, Dasgupta), Research Institute of the McGill University Health Centre; Department of Pediatrics (Nakhla), Division of Endocrinology and Metabolism, McGill University, Montréal, Que.

Contributors: Kaberi Dasgupta, Elham Rahme and Meranda Nakhla conceived of and designed the work and obtained funding. Andrea Blotsky performed the initial round of analyses under the supervision of Kaberi Dasgupta and Elham Rahme. Andrea Blotsky wrote the first draft of the manuscript under the supervision of Kaberi Dasgupta. The analyses were subsequently rerun by Mourad Dahhou under the supervision of Kaberi Dasgupta and Elham Rahme. The manuscript was revised by Kaberi Dasgupta, Elham Rahme and Meranda Nakhla. All of the authors revised the manuscript critically for important intellectual content, gave final approval of the version to be published and agreed to be accountable for all aspects of the work.

Funding: This study was supported by an operating grant from Diabetes Canada (principal investigator Kaberi Dasgupta; co-principal investigator Elham Rahme). The funding source had no role in study design, data collection, data analysis, data interpretation, or writing of the report. Kaberi Dasgupta was supported by a senior clinician scientist salary award from the Fonds de recherche du Québec - Santé (FRQS). Meranda Nakhla was supported by a junior clinician scientist salary award from the FRQS.

Data sharing: Data are not available for sharing.

Accepted: Mar. 22, 2019

Correspondence to: Kaberi Dasgupta, kaberi.dasgupta@mcgill.ca 